\title{
FEeding SELECTIVITY OF MONTANE AND LONG-TAILED VOLES (Microtus montanus and M. longicaudus)
}

\author{
FREDERICK J. JANNETT, JR. $\bullet$ DEPARTMENT OF BIOLOGY \\ THE SCIENCE MUSEUM OF MINNESOTA $\diamond$ ST. PAUL
}

\section{$\checkmark$ OBJECTIVES}

The purpose of the research, begun in 1989, is to ascertain how selectively voles feed, and to assess vegetation as a factor in demographic processes. Microtus longicaudus exhibits relatively stable numbers while $M$. montanus has dramatic fluctuations in some habitats. The study sites for $M$. montanus have been chosen to include primary and secondary habitat, and proximate and isolated habitat patches. Vegetation has heretofore not been quantitatively analyzed.

\section{$\checkmark \quad$ METHODS}

Virtually all previous work on these species by the author (1971-1977, and $1982-1988)$ involved live trapping. The work of interest requires specimens obtained in Museum Special traps for stomach content analysis. The trapping begun in 1989 is a preliminary effort, the first purpose of which was to assess the efficacy of Museum Special traps. The number of sites where $M$. longicaudus is found is being increased across a spectrum of vegetation types. Only three populations of this species were monitored from 1982-1988. Also, at three sites with populations of $M$. montanus, live traps are still deployed to secure voles; it is hoped that, by replicating previous efforts at these three sites, work on food habits can be related to possible changes in vole numbers. For this end the three sites chosen for continued monitoring with live traps are; one field having definite population fluctuations, one site peripheral to primary habitat, and one site of secondary habitat.

There were few $M$. montanus in the three regularly scheduled samples and few voles of any species elsewhere in lines to locate $M$. longicaudus; additional samples were made to ascertain the extent of the generally low numbers. Two of the three sites where $M$. longicaudus populations were followed and three of the 18 with $M$. montanus were resampled in 1993 with the same previous efforts (1982-1988).

Most trapping periods were limited to two days so that impact on the respective populations would be minimized. From fresh specimens, eyes were removed for age determination based upon lens weight (Gourley and Jannett, 1975).

\section{$\checkmark \quad$ RESULTS}

At two sites the populations of $M$. montanus decreased from October, 1992 to October, 1993 by $47 \%$ and $77 \%$, respectively. But in secondary habitat, the number of voles in the sample (4) for the last two years nearly remained constant (5). The populations at the other $M$. montanus sites were very low. The largest sample was 13 , in primary habitat.

Breeding continued in two of the six populations of $M$. montanus in October. Of seven apparently parous females, one was pregnant or lactating. Males with scrotal or nearly scrotal testes were found only at the two sites with reproductively 
active female(s). The sex ratios (males:females) of reproductively active in these two populations were $1: 0.33$ and $1: 2.0$, respectively.

Microtus longicaudus were obtained in only one of three new sites surveyed. Very few mammals of any species were obtained at the other two sites, which were along small streams. At both of these sites there was evidence of carnivores. However, both of the sites where $M$. longicaudus were stable in 1982-1988 yielded numbers similar to those in previous years.

\section{- DISCUSSION}

Continued monitoring of representative $M$. montanus sites is showing the disparity in population size trends within one year. Whether there is concomitant disparity in morphological patterns among specimens awaits processing and analyses. It also shows, albeit with small numbers, the disparity in the degree to which females in different populations continue to breed in October. Most generalities about reproduction in "cycling" Microtus populations are applied to different years (e.g. Krebs and Myers, 1974) but differences exist within a year between different subsets of the metapopulation.

Eighteen populations of $M$. montanus were previously identified during 1982-1988, but only 16 of $M$. longicaudus have been "found" to date. I will identify 18 preliminary to vegetation and gut analyses. Negus and Findley (1959) secured no Microtus longicaudus from 17 quadrats in nine community types in and around Jackson Hole. They found it elsewhere and concluded that it was the least common species of Microtus in Jackson Hole. However, Clark and Stromberg (1987), in a more popular account, posited it in various habitats, including grassland and streamside. Long-term monitoring of $M$. montanus indicates $M$. longicaudus is uncommon in open grassland dominated by $M$. montanus, but otherwise does show considerable habitat breadth. Finding populations along streams may be problematic because of small carnivore activity there, but the problem in 1993 was probably exacerbated by generally low small mammal number.

\section{- ACKNOWLEDGEMENTS}

I thank the National Park Service for permission to work in Grand Teton National Park, and the University of Wyoming-National Park Service Research Center for its hospitality. This work was supported by the Science Museum of Minnesota.

\section{- LITERATURE CITED}

Clark, T. W. and M. R. Stromberg. 1987. Mammals in Wyoming. University of Kansas, Mus. Nat. Hist., Publ. Ed. Ser. No. 10, 314 pp.

Gourley, R. S. and F. J. Jannett, Jr. 1975. Pine and montane vole age estimates from eye lens weights. J. Wildl. Manage., 39: 550-556.

Jannett, F. J., Jr. 1978. The density-dependent formation of extended maternal families of the montane vole, Microtus montanus nanus. Behav. Ecol. Sociobiol., 3: 245-263.

Krebs, C. J. and J. H. Myers. 1974. Population cycles in small mammals. Adv. Ecol. Res., 8:267-399.

Negus, N. C. and J. S. Findley. 1959. Mammals of Jackson Hole, Wyoming. J. Mamm., 40: 371-381. 